\title{
Intra-articular Recombinant Human Growth Hormone Injection Compared with Hyaluronic Acid and Placebo for an Osteoarthritis Model of New Zealand Rabbits
}

\author{
Andri Maruli Tua Lubis, $\mathrm{MD}, \mathrm{PhD}^{1}$, Erick Wonggokusuma, $\mathrm{MD}^{2}$, and Aldo Fransiskus Marsetio, $\mathrm{MD}^{1}$ \\ ${ }^{1}$ Department of Orthopaedic and Traumatology, Faculty of Medicine, Universitas Indonesia and Department of Orthopaedic and Traumatology, Cipto Mangunkusumo \\ Hospital, Jakarta; ${ }^{2}$ Department of General Orthopaedic, Siloam Hospital Kebon Jeruk, Jakarta, Indonesia
}

\begin{abstract}
Purpose: Up to now, there is no feasible solution for stopping or reversing the degenerative process of osteoarthritis (OA). Our study evaluated the effect of intra-articular injection of growth hormone $(\mathrm{GH})$ in OA-induced rabbit knees compared to hyaluronic acid (HA) and placebo.

Materials and Methods: A total of 21 male, skeletally mature, New Zealand rabbits received an intra-articular type II collagenase injection for OA induction. Two weeks later, the rabbits were randomized into three groups based on the weekly intra-articular injection to be received: GH, HA, and saline. Injections were done for three consecutive weeks. Evaluation was done at 8 weeks after treatment, clinically using the lameness period, macroscopically using the Yoshimi score and microscopically using the Mankin score.

Results: The shortest period of lameness was found in the GH group (15.9 \pm 2.12 days), compared to the HA group (19.4 \pm 1.72 days) and placebo group (25.0 \pm 2.94 days). There was a statistically significant difference in macroscopic scoring between groups ( $\mathrm{p}=0.001)$ in favor of the GH group. There was also significant difference in the microscopic score between groups $(\mathrm{p}=0.001)$ also in favor of the GH group.

Conclusions: Intra-articular injection of GH showed better clinical, macroscopic and microscopic results as compared to HA and placebo.
\end{abstract}

Keywords: Knee, Osteoarthritis, Growth hormone, Hyaluronic acid

\section{Introduction}

Osteoarthritis (OA) is the most common form of arthritis which represents a group of synovial degenerative diseases that cause disturbance starting from the cellular level to the extracellular level ${ }^{1,2)}$. Chronic pain elicited by the disease limits movement and decreases the patient's quality of life ${ }^{3-5)}$.

Many pharmacological agents were trialed to relieve symptoms

Received October 22, 2018; Revised November 6, 2018;

Accepted November 17, 2018

Correspondence to: Aldo Fransiskus Marsetio, MD

Department of Orthopaedic and Traumatology, Cipto Mangunkusumo General Hospital, Jl. Diponegoro No. 71, Senen, Jakarta 10430, Indonesia Tel: +62-21-3155996, Fax: +62-21-3929655

E-mail: aldofransiskus@gmail.com

Source of funding: This research was funded by the postgraduate research grant Universitas Indonesia.

This is an Open Access article distributed under the terms of the Creative Commons Attribution Non-Commercial License (http://creativecommons.org/licenses/by-nc/4.0/) which permits unrestricted non-commercial use, distribution, and reproduction in any medium, provided the original work is properly cited. and alter the degenerated cartilage structure, but none has been proven satisfactory. Currently, the standard conservative treatment for OA is symptomatic (analgesics), either as monotherapy or in combinations. Hyaluronic acid (HA) is one of the most commonly used pharmacological agents. Studies have shown promising results of intra-articular injection of $\mathrm{HA}$, as it is able to alter the cartilage degeneration by means of chemical and mechanical mechanisms. However, the chondroprotective effect of HA was not proven ${ }^{4)}$. Co-injection of HA and recombinant human growth hormone $(\mathrm{GH})$ was found more effective in modifying structures and symptoms when compared to the injections of HA alone in OA-induced rabbits ${ }^{6}$. A new mono-endothelial vessel formation (morphoangiogenesis) was found after the concomitant intra-articular injections and is believed as a cartilage regeneration factor in $\mathrm{OA}^{6,7)}$.

$\mathrm{GH}$ is known able to stimulate cell growth, reproduction and regeneration. It is made in the anterior pituitary gland, secreted by somatotropic cells to the blood stream and stimulates insulin-like growth factor-1 (IGF-1) production by the liver. This IGF-1 would 
promote growth effects on almost every cell in the body, especially the skeletal muscle, cartilage and bone. Research done by Dunn ${ }^{7)}$ revealed that morphoangiogenesis found in the knee injected with recombinant human $\mathrm{GH}$ played a role in cartilage regeneration.

Although found beneficial, the injection of intra-articular GH is still an 'off label' method because there is not enough evidence about the mechanism of $\mathrm{GH}$ in improving cartilage regeneration. We hypothesized that the sole intra-articular injection of $\mathrm{GH}$ is able to improve cartilage regeneration and provide a better outcome when compared to intra-articular injections of $\mathrm{HA}$. We conducted an in vivo clinical trial to examine the benefit of intraarticular injection of GH and explored the possibilities for clinical application.

\section{Materials and Methods}

\section{Study Design and Subject Selection}

We conducted an experimental research with the post-test only control group design at the teaching animal hospital and anatomic pathology laboratory of faculty of veterinary medicine, Bogor Agricultural University, Indonesia.

As many as 21 skeletally mature male New Zealand rabbits that weigh $2,000 \mathrm{~g}$ to 2,500 $\mathrm{g}$ free of deformities on all lower limbs were used as subjects. The subjects were acclimatized in a modified room temperature ranging $18^{\circ} \mathrm{C}-21^{\circ} \mathrm{C}$ with humidity of $55 \%$ and were given dry food ( $5 \mathrm{~g}$ per $100 \mathrm{~g}$ body weight). To reduce experimental bias, randomization of the subjects and blinding to drug preparation and the attending veterinarian responsible for evaluation were done (Fig. 1).

\section{Preliminary Study and Drug Administration}

A preliminary study of OA induction by intra-articular collagenase injections was done. The knee of the hind leg was shaved and disinfected using povidone iodine. Intramuscular injection of anesthetic agents, xylazine $(1.9 \mathrm{mg} / \mathrm{kg}$ body weight) and ketamine (46 mg/kg body weight), was done. Two milligrams of type II collagenase extracted from Clostridium histolyticum (enzyme activity 425 U/mg; Sigma-Aldrich, St. Louis, MO, USA) was dissolved in $0.5 \mathrm{~mL}$ sterile phosphate-buffered saline solution and filtered through a $0.22 \mu \mathrm{m}$ membrane. The solution was then injected with pre-filtered saline phosphate $(\mathrm{pH} 7.4)$ to the knee joint. The second injection was done 3 days after the first injection. The destruction effect from these injections was expected in 2 weeks after the second injection.

Different treatment was given two weeks after the OA induction. Randomization was done and the subjects were divided into three groups in respect of their treatment (placebo, HA, and $\mathrm{GH})$. The injection was done with $1 \mathrm{~mL} 26 \mathrm{G}$ syringe. The HA treatment group was injected with $1 \mathrm{~mL}(10 \mathrm{mg})$ of sodium hyaluronate (Osflex; Novell Pharmaceutical Laboratories, Jakarta,

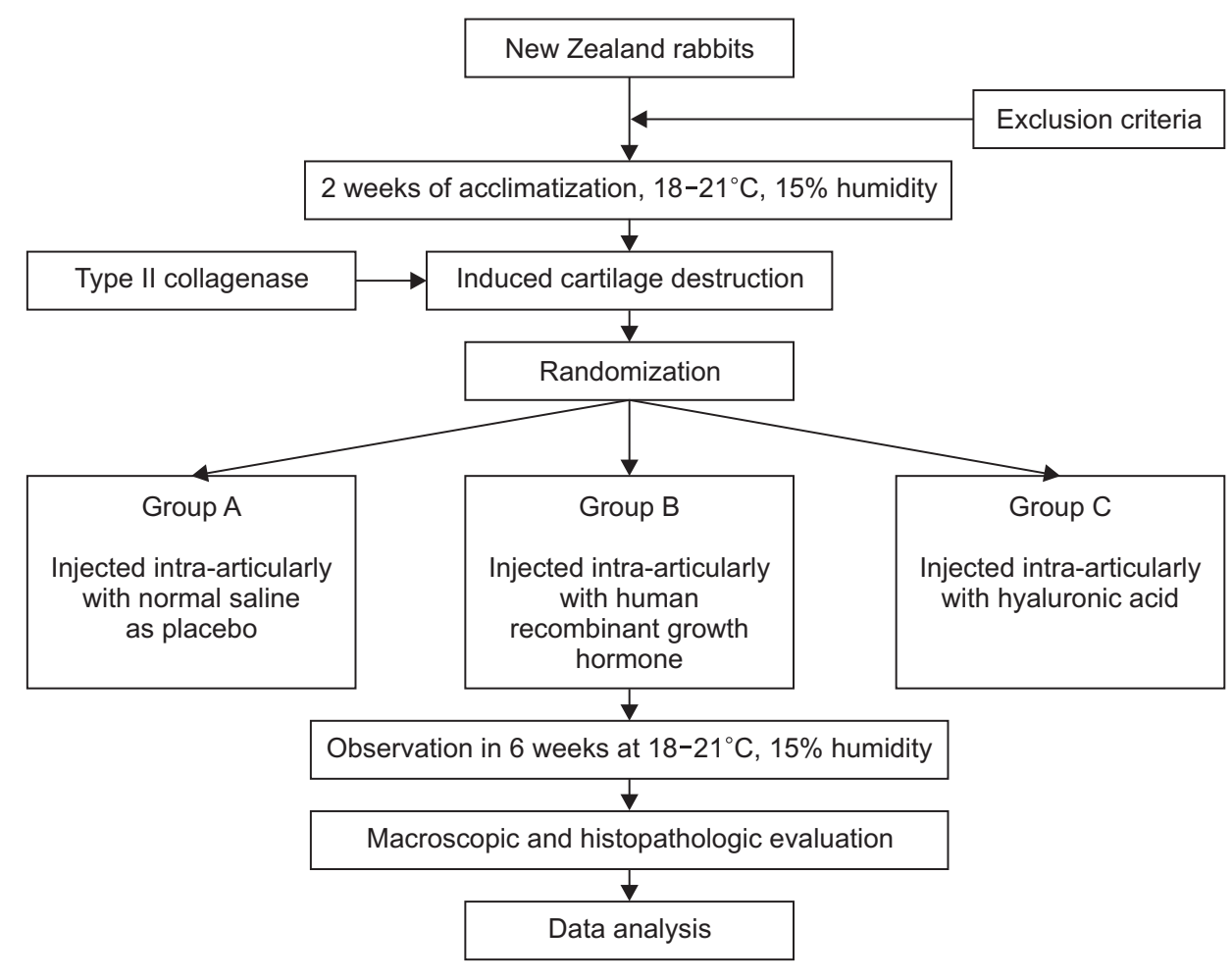

Fig. 1. Research diagram. 
Indonesia). The GH treatment group was injected with $1 \mathrm{~mL}(4$ IU) of recombinant human somatropin (Novell Eutropin, Novell Pharmaceutical Laboratories). The placebo group was injected with $1 \mathrm{~mL}$ of normal saline. The subjects were then returned to the cage and observed daily for limping gait (lameness) and body weight changes for 8 weeks after the first injection. After 8 weeks, all of the subjects were euthanized using intravenous phenobarbital (10 mg/kg).

\section{Evaluation}

After the injection treatment and before the euthanasia, the subjects were clinically observed for lameness period. At 8 weeks after treatment, macroscopic changes were evaluated using structural criteria suggested by Yoshimi et al. ${ }^{8)}$. Histopathologic examination was also performed to assess the degree of cartilage changes according to the scoring system of Mankin ${ }^{9)}$. After euthanasia, specimens obtained from the lateral condyle of the femur were taken for histopathological examination, decalcified with $20 \%$ ethylenediaminetetraacetic acid, and fixed with $10 \%$ buffered formalin. Slicing was done for 5 slices ( $5 \mathrm{~mm}$ thick coronal cuts) and staining using hematoxylin-eosin was done. Scoring system details are presented in Table 1.

\section{Statistical Analysis}

Statistical analysis was done using IBM SPSS ver. 20.0 (IBM Corp., Armonk, NY, USA), using analysis of variance (ANOVA) test and non-parametric Mann-Whitney test. Based on the Federer formula, the minimum sample size required for the study was 8 samples for each group. However, the ethical clearance committee only allowed us to proceed with the total samples of 21 rabbits. The ANOVA parametric test and Mann-Whitney non-parametric test were performed to analyze the correlation between study groups. The results were considered statistically significant if $\mathrm{p}$-value was less than 0.05 .

\section{Ethical Clearance}

This study obtained ethical approval from the Animal Hospital of Bogor Botanical Institute (RSH IPB) Ethical Committee (no. 02-2015 RSH-IPB).

\section{Results}

\section{Induction of Osteoarthritis}

A preliminary study was done to evaluate the time needed for type II collagenase to degenerate cartilage tissue of the subject's knee in order to mimic full-blown OA. After two weeks, evaluation was done macroscopically and microscopically. Destruction of cartilage was evident macroscopically (Fig. 2), and fissure on the radial zone and hypocellularity of the chondrocytes were evident microscopically (Fig. 3); thus, confirming the characteristics of OA.

\section{Evaluation of Lameness Period}

The longest lameness period was observed in the control group (mean, 25 days) with the shortest lameness period found in the GH group (mean, 15.9 days), and the HA group's lameness period was found in between (mean, 19.4 days). Significant difference was found between the control, HA group and GH group $(p<0.001)$, the HA group and the control group $(p=0.001)$, the control and GH group $(\mathrm{p}<0.001)$ and the HA group and $\mathrm{GH}$ group $(\mathrm{p}=0.030)$ (Table 2$)$.

\section{Evaluation of Macroscopic Parameters after 8 Weeks of Treatment}

For macroscopic evaluation, the Yoshimi scoring system was used (Tables 3, 4). According to the Saphiro-Wilk test, the Yoshimi score from the control group and HA group showed a normal data distribution ( $\mathrm{p}=0.062$ and $\mathrm{p}=0.086$ ), meanwhile the Yoshimi score from the GH group did not have a normal data distribution

Table 1. Parameters Used in the Study to Evaluate Clinical and Structural Changes ${ }^{8,9,14,18,27)}$

Lameness period to evaluate clinical changes: the time required by the rabbit to be able to hop normally again (using both of its hind legs) since the induction of osteoarthritis

Yoshimi score to evaluate macroscopic changes:

0) Normal cartilage

1) Soften cartilage

2) Cartilage fibrillation

3) Cartilage erosion

4) Ulceration

5) Defected cartilage
Mankin score to evaluate microscopic changes:

0) Normal

1) Irregular cartilage surface

2) Irregular cartilage surface with pannus

3) Tear into the transitional zone

4) Tear into the radial zone

5) Tear into the calcification zone

6) Total disorganization of cartilage 

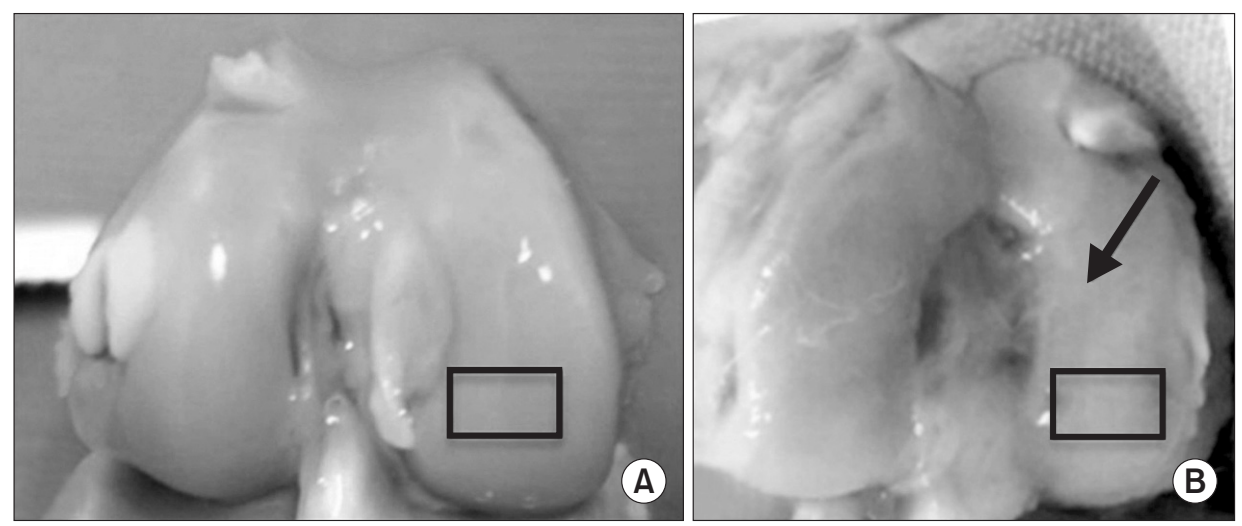

Fig. 2. Macroscopic appearance of the osteoarthritis-induced knee, showing ulceration and no regeneration, compared to the healthy opposite knee of the same rabbit in the preliminary study. (A) Healthy knee. (B) Osteoarthritis-induced knee. Arrow: ulceration.
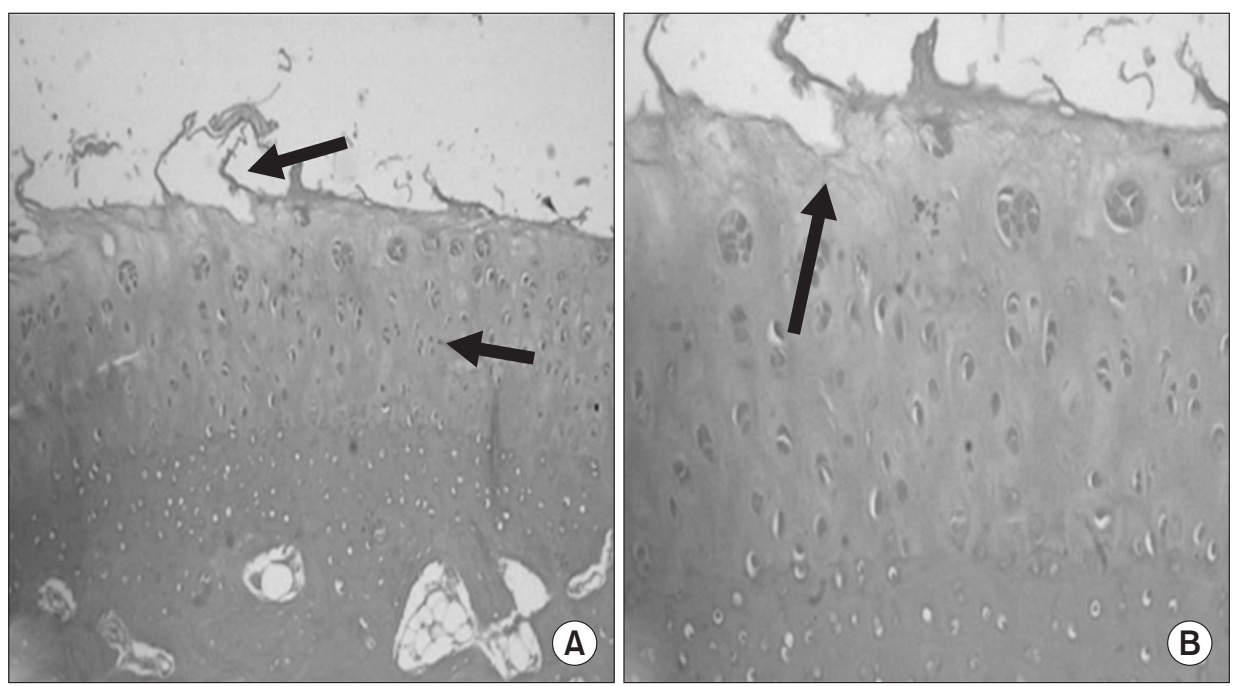

Fig. 3. Microscopic examination of the osteoarthritis-induced knee $(\mathrm{H} \& \mathrm{E}, \mathrm{A}: \times 40, \mathrm{~B}$ : $\times 100)$ showing fissures and hypocellularity in the preliminary study. (A) Upper arrow: fissures, lower arrow: hypocellularity. (B) Arrow: fissures.
Table 2. Statistical Analysis of Lameness Period

\begin{tabular}{lccr}
\hline \multicolumn{1}{c}{ Group } & Mean \pm SD & Statistic test & p-value \\
\hline Control & $25.0 \pm 2.9$ & Shapiro-Wilk test & 0.863 \\
HA & $19.4 \pm 1.7$ & & 0.958 \\
GH & $15.9 \pm 2.1$ & & 0.133 \\
Control vs. HA vs. GH & & One-way ANOVA test & $<0.001$ \\
Control vs. HA & & Post-hoc Bonferroni test & 0.001 \\
Control vs. GH & & Post-hoc Bonferroni test & $<0.001$ \\
HA vs. GH & & Post-hoc Bonferroni test & 0.030 \\
\hline
\end{tabular}

SD: standard deviation, HA: hyaluronic acid, GH: growth hormone, ANOVA: analysis of variance.

$(\mathrm{p}=0.001)$. The Kruskal-Wallis test showed a statistically significant difference for Yoshimi score between the control, HA group and $\mathrm{GH}$ group ( $\mathrm{p}=0.001$ ). Using the mean difference test between two groups, significant difference was found between the control group and the HA group (independent $t$-test, $\mathrm{p}=0.004$ ), the control and GH group (Mann-Whitney test, $\mathrm{p}=0.001$ ), and the HA group and GH group (Mann-Whitney test, p=0.040) (Fig. 4).

\section{Evaluation of Histopathological Score}

A modified Mankin scoring system was used for histopathological evaluation of the subject's cartilage. According to the SaphiroWilk test, the Mankin score from the control and GH group had a normal data distribution ( $\mathrm{p}=0.609$ and $\mathrm{p}=0.086$, respectively), and HA group did not have a normal data distribution $(\mathrm{p}<0.05)$. The Kruskal-Wallis test found a statistically significant difference between the control, HA group and GH group in favor of the $\mathrm{GH}$ group $(\mathrm{p}=0.001)$. Significant difference was found between the control and GH group ( $\mathrm{p}=0.001$ ), HA group and GH group $(\mathrm{p}=0.015)$ and control and HA group $(\mathrm{p}=0.020)$ (Tables 5, 6).

\section{Correlation between Yoshimi Score and Mankin Score}

Spearman analysis found that there was a significant strong correlation $(\mathrm{r}=0.768)$ between the Yoshimi score and Mankin score $(\mathrm{p}<0.001)$. 
Table 3. Statistical Analysis of Macroscopic Evaluation Using Yoshimi Scoring

\begin{tabular}{lcccccccc}
\hline \multirow{2}{*}{ Group } & \multicolumn{2}{c}{ Saphiro-Wilk test } & & \multicolumn{3}{c}{ Yoshimi score } \\
\cline { 2 - 3 } \cline { 6 - 8 } & Mean \pm SD (range) & p-value & & Mean \pm SD (range) & \multicolumn{2}{c}{ Median } & p-value \\
\hline Control & $3.9 \pm 0.9$ & 0.062 & & $3.86 \pm 0.9(3-5)$ & 4 & 0.062 \\
Hyaluronic acid & $2.3 \pm 0.8$ & 0.086 & & $2.29 \pm 0.8(1-3)$ & 2 & 0.086 \\
Growth hormone & $1.4 \pm 0.5(1-2)$ & 0.001 & & $1.43 \pm 0.5(1-2)$ & 1 & 0.001 \\
\hline
\end{tabular}

SD: standard deviation.
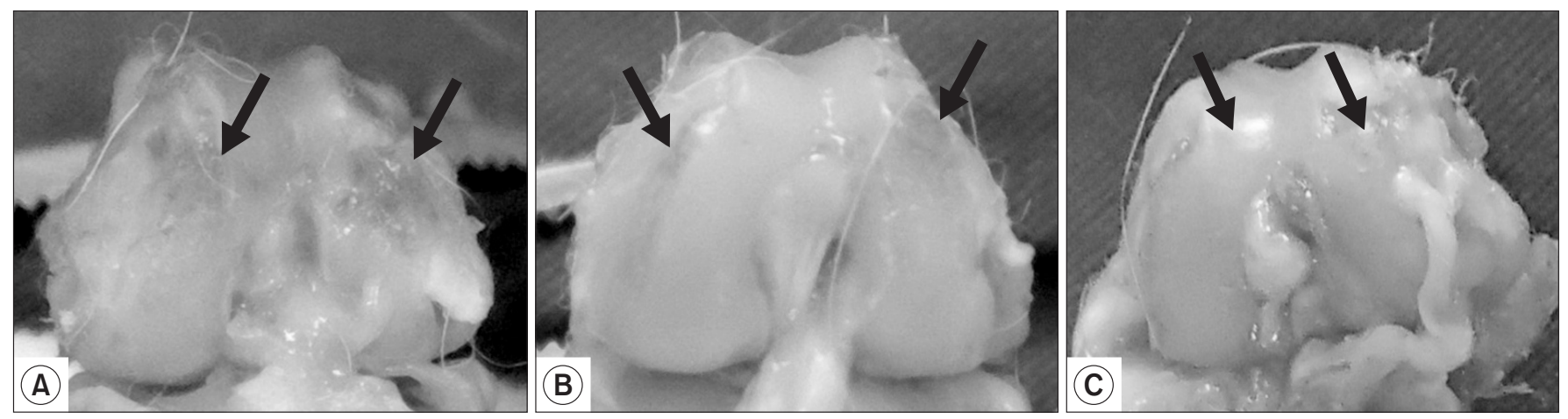

Fig. 4. Macroscopic appearance of the femoral condyle joints in three different treatment groups: control group (A), hyaluronic acid group (B), and growth hormone group (C). We can still see ulceration (arrows) (A), erosion of cartilage (arrows) (B), and softened cartilage (arrows) (C).

Table 4. Group Comparison of Macroscopic Evaluation Using Yoshimi Scoring

\begin{tabular}{llc}
\hline \multicolumn{1}{c}{ Group } & \multicolumn{1}{c}{ Statistic test } & p-value \\
\hline Control vs. HA vs. GH & Kruskal-Wallis test & 0.001 \\
Control vs. HA & Independent $t$-test & 0.004 \\
Control vs. GH & Mann-Whitney test & 0.001 \\
HA vs. GH & Mann-Whitney test & 0.040 \\
\hline
\end{tabular}

Table 6. Group Comparison of Microscopic Evaluation Using Mankin Scoring

\begin{tabular}{llc}
\multicolumn{1}{c}{ Group } & \multicolumn{1}{c}{ Statistic test } & p-value \\
\hline Control vs. HA vs. GH & Kruskal-Wallis test & 0.001 \\
Control vs. HA & Mann-Whitney test & 0.020 \\
Control vs. GH & Independent t-test & 0.001 \\
HA vs. GH & Mann-Whitney test & 0.015 \\
\hline
\end{tabular}

Table 5. Statistical Analysis of Microscopic Evaluation Using Mankin Scoring

\begin{tabular}{|c|c|c|c|c|c|}
\hline \multirow{2}{*}{ Group } & \multicolumn{2}{|c|}{ Saphiro-Wilk test } & \multicolumn{3}{|c|}{ Mankin score } \\
\hline & Mean \pm SD (range) & $\mathrm{p}$-value & Mean \pm SD (range) & Median & $\mathrm{p}$-value \\
\hline Control & $6.4 \pm 1.0$ & 0.609 & $6.4 \pm 1.0(5-8)$ & 6 & 0.609 \\
\hline Hyaluronic acid & $5.3 \pm 0.5(5-6)$ & $<0.001$ & $5.3 \pm 0.5(5-6)$ & 5 & $<0.001$ \\
\hline Growth hormone & $4.3 \pm 0.8$ & 0.086 & $4.3 \pm 0.8(3-5)$ & 4 & 0.086 \\
\hline
\end{tabular}

SD: standard deviation.

\section{Discussion}

Our study hypothesized that sole intra-articular injection of $\mathrm{GH}$ would be able to improve cartilage regeneration and provide a better outcome when compared to intra-articular injections of HA. The end result of this study found that GH injection is able to aid cartilage regeneration and is proven clinically, microscopi- cally and macroscopically better than HA injection.

\section{Subject Selection}

In this study we used white New Zealand rabbits because the subjects have similar anatomy with human cartilage and are easy to maintain and handle during treatment at an affordable cost. Male rabbits were chosen because they have higher survival rates 
than females. Rabbits with a minimum age of 7-8 months were chosen to ensure skeletal maturity, which occurs at 6 months of age. The weight of the rabbits in our study ranged from $1,900 \mathrm{~g}$ to $2,500 \mathrm{~g}$, in which the amount of knee joint synovial fluid is equal to $0.8-1.0 \mathrm{~mL}^{6)}$.

\section{OA Induction on the Knee Joint}

In this study, we chose collagenase clostridium hystolyticum type II (Sigma-Aldrich), a proteolytic enzyme, to induce OA on the rabbit's knee. It causes damage on the articular cartilage through the breakdown of the collagen and glycosaminoglycan, the main composition of cartilage matrix structure ${ }^{10,11)}$. This method was first used by Chu et al. ${ }^{12)}$ : they used various dosages and time intervals and concluded that the optimum dose to induce knee OA was $2 \mathrm{mg}$ with a 3 -day interval. Some studies found that there would be no regeneration or sign of healing of the rabbit's cartilage within two weeks up to twelve weeks after the injec- tion $^{6,10,11,13)}$. Inducing OA chemically using the proteolytic enzyme is superior for analyzing the pathology of articular cartilage compared to other techniques such as meniscectomy and anterior cruciate ligament resection because it mimics the natural process of OA in humans ${ }^{6,7,13)}$. Collagenase can be reproduced better than papain $^{10)}$ and non-surgical method is easier to use with lower cost and produce better survivability of rabbits.

\section{Clinical Effect of Growth Hormone}

Joint pain is the main parameter in evaluating the outcome of OA therapy ${ }^{6,14)}$. The pain may be caused by the cartilage defect and various inflammation factors, triggering limping gait (lameness) on the subjects. After the treatment, we found the lowest lameness period was in the GH group (15.9 \pm 2.12 days), compared to the HA group (19.4 \pm 1.72 days) and placebo group (25.0 \pm 2.94 days). Although this finding is similar to the study done by Kim et al. ${ }^{6}$, the lameness period was longer than that in
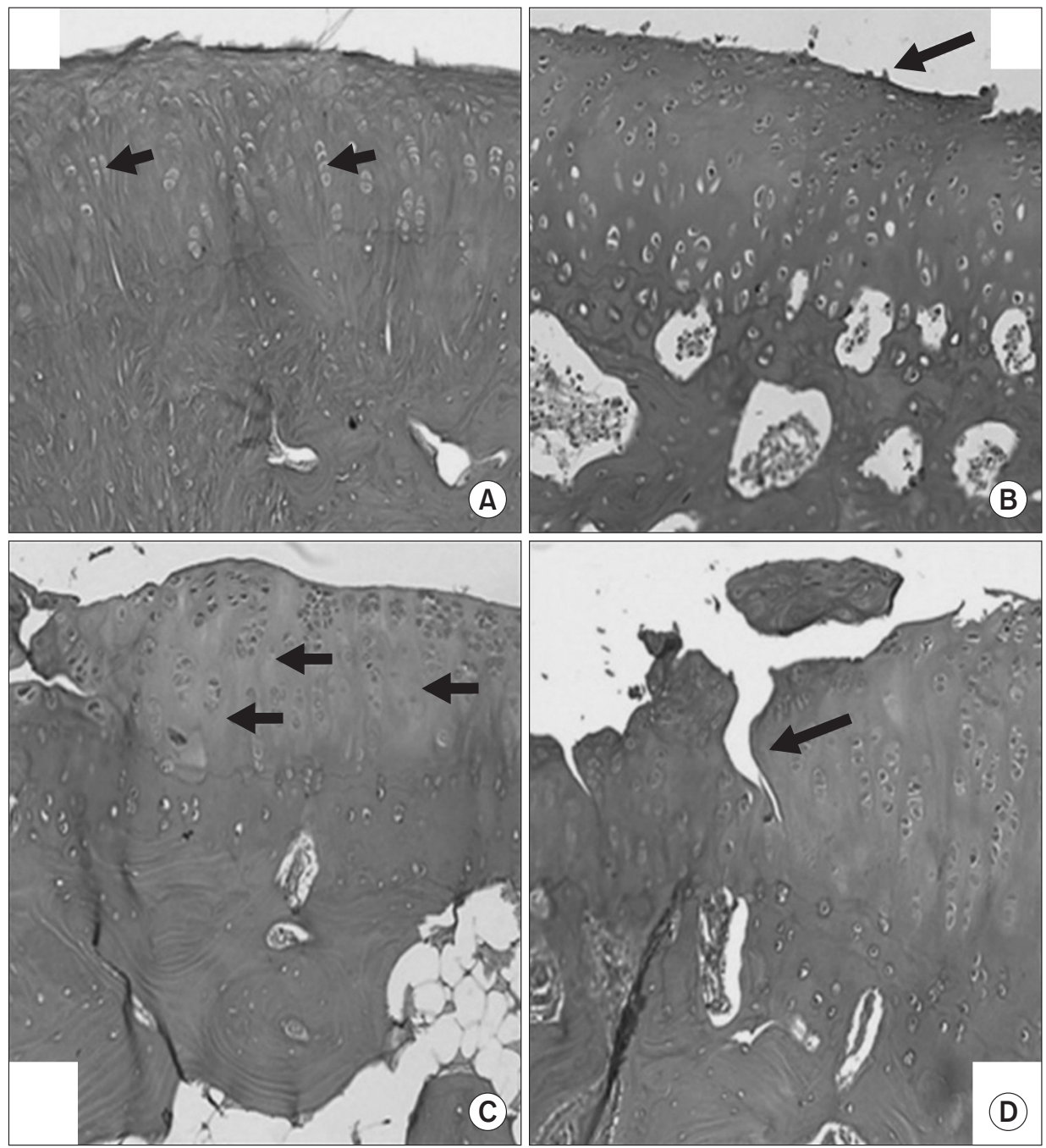

Fig. 5. Histopathological slides from the control group (H\&E). (A) Cloning (arrows) is evident on $\times 40$ magnification. (B) The cartilage surface is irregular (arrow) on $\times 100$ magnification. Evidence of more damage is seen with hypocellularity $(\mathrm{C}$; arrows) and radial zone tearing $(\mathrm{D}$; arrow) on $\times 100$ magnification. 
other studies ${ }^{15)}$.

Injection of $\mathrm{GH}$ as a single agent does not have mechanical effect or local anti-inflammatory effect at the joint ${ }^{8,16)}$. The effect of $\mathrm{GH}$ in overcoming inflammatory pain is through the indirect role of cortisol and IGF-1 which suppress the inflammatory process and prostaglandin that act as the pain mediator ${ }^{14,17)}$. The assessment of pain scale in this study was highly dependent on the observer. However, we minimized the bias by using a blind evaluation method. Gibson and Donnelly ${ }^{18)}$ found that observation of lameness period in rabbits has low reproducibility and a high inter- and intra-observer variability.

\section{Macroscopic and Microscopic Evaluation of Cartilage}

Microscopic and macroscopic assessment of cartilage is the best method to quantify the level of damage caused by the process of $\mathrm{OA}$ and its healing. The significant differences in Yoshimi scores between treatment groups in our study indicate that the healing process was better in the GH group and GH may have a positive effect for OA of the knee when compared to HA. This finding is similar to the study by Kim et al. ${ }^{6}$ even though they compared the combination of HA with GH to HA and placebo ${ }^{19)}$.

Our study used a modified Mankin scoring system for its good accuracy, high intra- and inter-observer reproducibility, and easiness to use $\mathrm{e}^{6,20,21)}$. Significant differences in scoring between the groups with GH group showing the best score are similar to those in other studies that found the healing of the cartilage can occur after the intra-articular injection of $\mathrm{GH}^{6,8,15)}$. Although the mechanism of regeneration of cartilage after the injection of GHs is not fully understood, Dunn ${ }^{7)}$ discovered a process of neovascularization, wherein there are layers of neocapillary blood vessels that penetrate the bone layer. This morphoangiogenesis process is important in producing stem cells that eventually play a role in the regeneration of cartilage. Additionally, our histopathological examination found a form of glomeruloid in the GH group, which is characterized as fenestrated small arteries. This structure was not found in the placebo group and HA group (Fig. 5, 6).
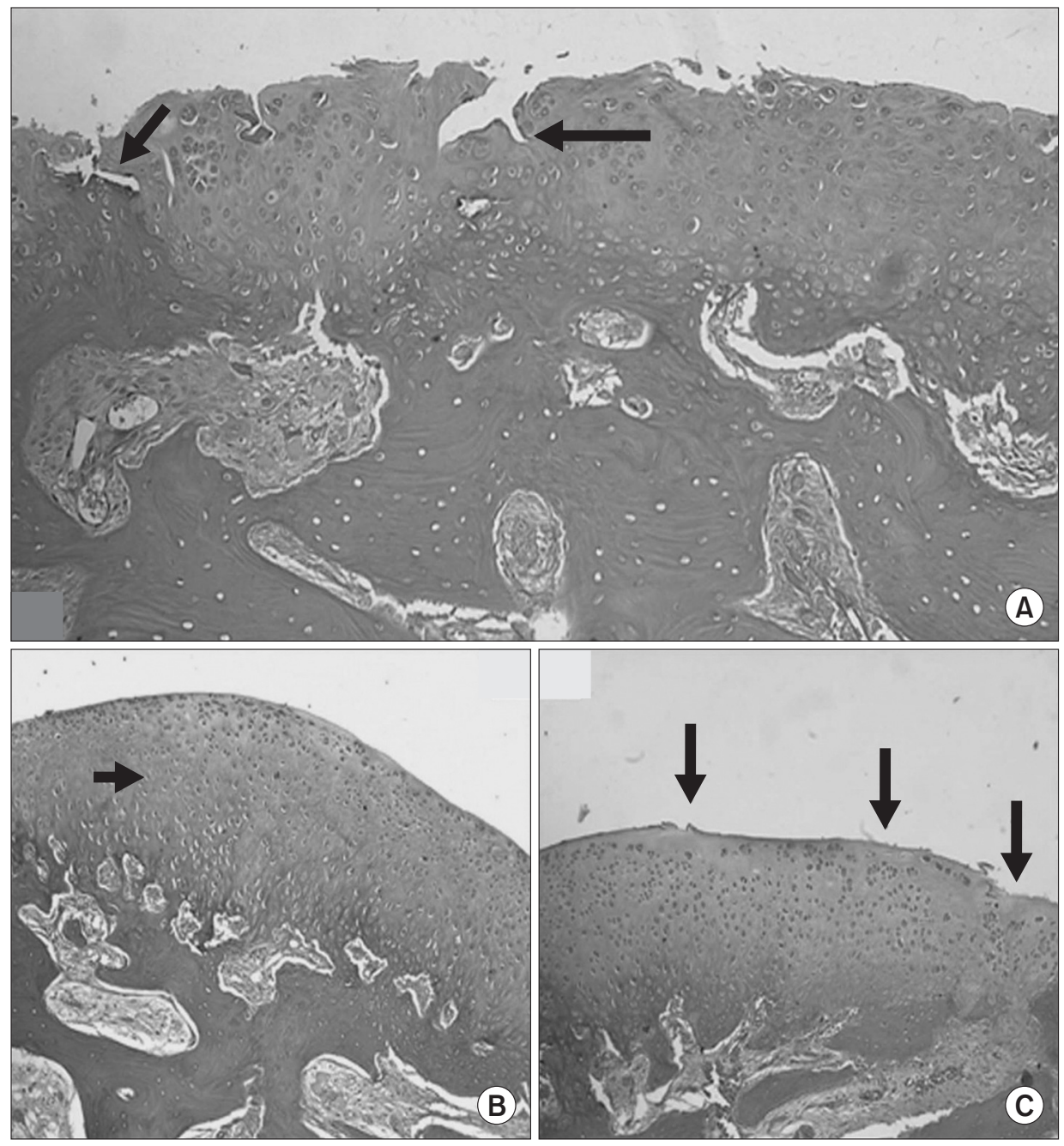

Fig. 6. Histopathological slides from the hyaluronic acid group (H\&E). (A) Tearing on the transitional zone (arrows) is seen on $\times 40$ magnification. (B) Diffuse hypercellularity (arrow) on $\times 40$ magnification. (C) Superficial surface of joint cartilage is missing (arrows) on $\times 40$ magnification. 

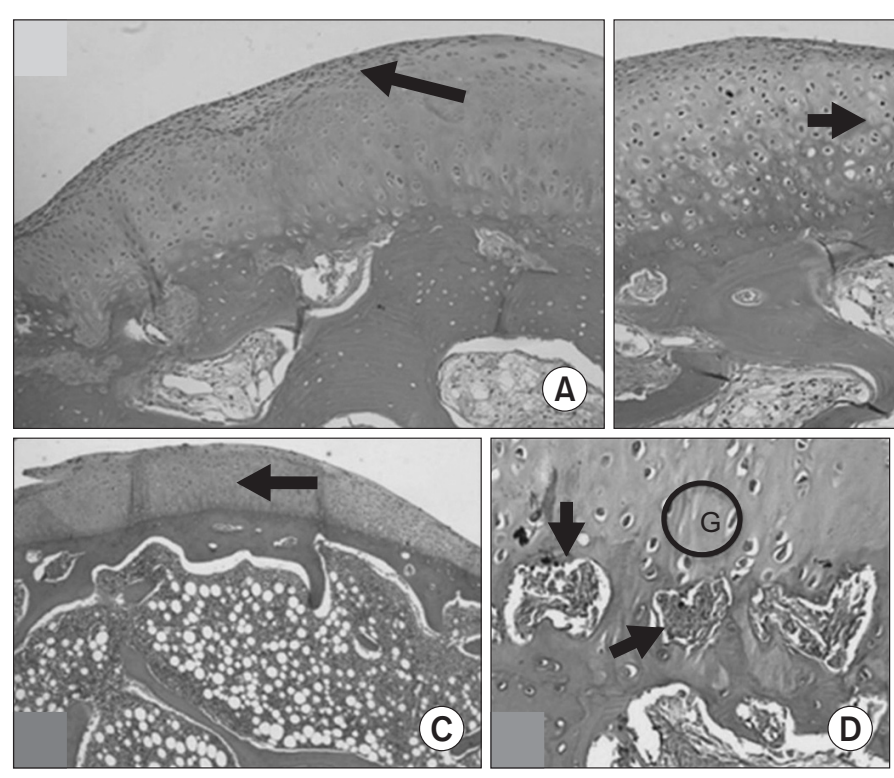

According to Iwamoto et al. ${ }^{15)}$, GH affects chondrocytes indirectly through the function of IGF-1, stimulating them to be active and proliferate. This finding was also supported by Kolbeck et al. ${ }^{22)}$. Hypercellularity of the knee cartilage histologically was also found higher in the GH group than other groups meaning that healing may have taken place in the GH group (Fig. 7).

Intermediate-weight $\mathrm{HA}\left(1.2 \times 10^{6} \mathrm{Da}\right)$ with $3 \times$ injections was used as a comparison to $\mathrm{GH}$ due to its properties that needed 3-5 times of injection to mimic the dose that we used for intraarticular GH injections ${ }^{23)}$. Lower molecular weight $\mathrm{HA}$ is easier to inject to the narrow knee of the rabbit because it is less viscous than the high molecular weight HA. We injected $6 \mathrm{mg}$ HA using $26 \mathrm{G}$ similar to the research done by Mihara et al. ${ }^{19)}$ and Kobayashi et al. ${ }^{24)}$ where the use of different molecular weight HA showed a synergistic effect. Various literatures exposed controversies between the use of low molecular HA and high molecular HA in OA. Yoshimi et al. ${ }^{8)}$ and Brockmeier and Shaffer ${ }^{25)}$ stated that high molecular HA delivers better results than low molecular $\mathrm{HA}^{16)}$ while Atay et $\mathrm{al}^{26)}$, and Kotevglu et al. ${ }^{23)}$ reported that there are no significant differences in the case of intra-articular HA injection for OA.

Based on our findings, we conclude that the $\mathrm{GH}$ provides a better effect than placebo and HA for osteoarthritic joints. The pathophysiology of healing may be related to the new vascular structures that were found in the microscopic evaluation. Regardless of the positive findings, our study has some inevitable limitations and further research may be necessary. This study might have shown better results if it fulfilled the adequate sample size; although the calculated minimum sample size was 24 , our
Animal Ethical Committee approved only 21 samples. In addition, we only evaluated a single dose of GH (4 IU); perhaps the use of various doses would help determine the optimal dose of $\mathrm{GH}$ for the best result. Longer evaluation time may also a good point to explore further in order to have an insight for long-term results or possible side effects.

\section{Conclusions}

Intra-articular injection of $\mathrm{GH}$ as a single agent gives a better result in terms of clinical, macroscopic and microscopic findings in New Zealand rabbits with knee OA, serving as a possible alternative for treatment of $\mathrm{OA}$. However, more research still needs to be done on the optimal GH dose, long-term results, GH serum level measurement and any possible side effects.

\section{Conflict of Interest}

No potential conflict of interest relevant to this article was reported.

\section{Acknowledgments}

Authors would like to thank the department of Orthopaedic and Traumatology, Faculty of Medicine, Universitas Indonesia and Faculty of Veterinary Medicine, Bogor Agricultural University. 


\section{References}

1. Iijima $\mathrm{H}$, Aoyama T, Ito A, Tajino J, Nagai $\mathrm{M}$, Zhang $\mathrm{X}$, Yamaguchi S, Akiyama H, Kuroki H. Destabilization of the medial meniscus leads to subchondral bone defects and sitespecific cartilage degeneration in an experimental rat model. Osteoarthritis Cartilage. 2014;22:1036-43.

2. Kuijt MT, Inklaar H, Gouttebarge V, Frings-Dresen MH. Knee and ankle osteoarthritis in former elite soccer players: a systematic review of the recent literature. J Sci Med Sport. 2012;15:480-7.

3. Sagar DR, Nwosu L, Walsh DA, Chapman V. Dissecting the contribution of knee joint NGF to spinal nociceptive sensitization in a model of OA pain in the rat. Osteoarthritis Cartilage. 2015;23:906-13.

4. Muramatsu Y, Sasho T, Saito M, Yamaguchi S, Akagi R, Mukoyama S, Akatsu Y, Katsuragi J, Fukawa T, Endo J, Hoshi H, Yamamoto Y, Takahashi K. Preventive effects of hyaluronan from deterioration of gait parameters in surgically induced mice osteoarthritic knee model. Osteoarthritis Cartilage. 2014;22:831-5.

5. Fuchsjager-Mayrl G, Pleiner J, Wiesinger GF, Sieder AE, Quittan M, Nuhr MJ, Francesconi C, Seit HP, Francesconi M, Schmetterer L, Wolzt M. Exercise training improves vascular endothelial function in patients with type 1 diabetes. Diabetes Care. 2002;25:1795-801.

6. Kim SB, Kwon DR, Kwak H, Shin YB, Han HJ, Lee JH, Choi SH. Additive effects of intra-articular injection of growth hormone and hyaluronic acid in rabbit model of collagenase-induced osteoarthritis. J Korean Med Sci. 2010;25:77680.

7. Dunn AR. Morphoangiogenesis: a unique action of growth hormone. Microvasc Res. 2002;63:295-303.

8. Yoshimi T, Kikuchi T, Obara T, Yamaguchi T, Sakakibara Y, Itoh $\mathrm{H}$, Iwata $\mathrm{H}$, Miura T. Effects of high-molecular-weight sodium hyaluronate on experimental osteoarthrosis induced by the resection of rabbit anterior cruciate ligament. Clin Orthop Relat Res. 1994;(298):296-304.

9. Glasson SS, Chambers MG, Van Den Berg WB, Little CB. The OARSI histopathology initiative: recommendations for histological assessments of osteoarthritis in the mouse. Osteoarthritis Cartilage. 2010;18 Suppl 3:S17-23.

10. Adaes S, Mendonça M, Santos TN, Castro-Lopes JM, Ferreira-Gomes J, Neto FL. Intra-articular injection of collagenase in the knee of rats as an alternative model to study nociception associated with osteoarthritis. Arthritis Res
Ther. 2014;16:R10.

11. Kwon DR, Park GY, Lee SU. The effects of intra-articular platelet-rich plasma injection according to the severity of collagenase-induced knee osteoarthritis in a rabbit model. Ann Rehabil Med. 2012;36:458-65.

12. Chu CR, Szczodry M, Bruno S. Animal models for cartilage regeneration and repair. Tissue Eng Part B Rev. 2010;16:10515.

13. Huh JE, Baek YH, Lee JD, Choi DY, Park DS. Therapeutic effect of Siegesbeckia pubescens on cartilage protection in a rabbit collagenase-induced model of osteoarthritis. J Pharmacol Sci. 2008;107:317-28.

14. ACLAM Task Force Members, Kohn DF, Martin TE, Foley PL, Morris TH, Swindle MM, Vogler GA, Wixson SK. Public statement: guidelines for the assessment and management of pain in rodents and rabbits. J Am Assoc Lab Anim Sci. 2007; 46:97-108.

15. Iwamoto $M$, Ohta $Y$, Larmour $C$, Enomoto-Iwamoto M. Toward regeneration of articular cartilage. Birth Defects Res C Embryo Today. 2013;99:192-202.

16. Hulmes DJ, Marsden ME, Strachan RK, Harvey RE, McInnes N, Gardner DL. Intra-articular hyaluronate in experimental rabbit osteoarthritis can prevent changes in cartilage proteoglycan content. Osteoarthritis Cartilage. 2004;12:2328.

17. Bennett R. Growth hormone in musculoskeletal pain states. Curr Rheumatol Rep. 2004;6:266-73.

18. Gibson CJ, Donnelly TM. Lameness in a rabbit. Lab Anim (NY). 2011;40:39-41.

19. Mihara M, Higo S, Uchiyama Y, Tanabe K, Saito K. Different effects of high molecular weight sodium hyaluronate and NSAID on the progression of the cartilage degeneration in rabbit OA model. Osteoarthritis Cartilage. 2007;15:543-9.

20. O'Driscoll SW. The healing and regeneration of articular cartilage. J Bone Joint Surg Am. 1998;80:1795-812.

21. Rutgers M, van Pelt MJ, Dhert WJ, Creemers LB, Saris DB. Evaluation of histological scoring systems for tissue-engineered, repaired and osteoarthritic cartilage. Osteoarthritis Cartilage. 2010;18:12-23.

22. Kolbeck S, Bail H, Schmidmaier G, Alquiza M, Raun K, Kappelgard A, Flyvbjerg A, Haas N, Raschke M. Homologous growth hormone accelerates bone healing: a biomechanical and histological study. Bone. 2003;33:628-37.

23. Kotevoglu N, Iyibozkurt PC, Hiz O, Toktas H, Kuran B. A prospective randomised controlled clinical trial comparing the efficacy of different molecular weight hyaluronan solu- 
tions in the treatment of knee osteoarthritis. Rheumatol Int. 2006;26:325-30.

24. Kobayashi Y, Okamoto A, Nishinari K. Viscoelasticity of hyaluronic acid with different molecular weights. Biorheology. 1994;31:235-44.

25. Brockmeier SF, Shaffer BS. Viscosupplementation therapy for osteoarthritis. Sports Med Arthrosc Rev. 2006;14:155-62.

26. Atay T, Aslan A, Baydar ML, Ceylan B, Baykal B, Kirdemir V.
The efficacy of low- and high-molecular-weight hyaluronic acid applications after arthroscopic debridement in patients with osteoarthritis of the knee. Acta Orthop Traumatol Turc. 2008;42:228-33.

27. Ostergaard K, Andersen CB, Petersen J, Bendtzen K, Salter DM. Validity of histopathological grading of articular cartilage from osteoarthritic knee joints. Ann Rheum Dis. 1999; 58:208-13. 